\title{
Imo Ade Awo: A Principle of Transcultural Humanist Philosophy of the Annang People of Akwa Ibom State, Nigeria
}

\author{
Dr. Joseph Alphonsus Okon \\ Department of Philosophy, Faculty of Arts/ Akwalbom State University, MkpatEnin, Akwalbom State, Nigeria
}

\begin{abstract}
Man, who is both a product and a producer of culture, often becomes the victim offin culture. As a victim in cultures, both his latent potentials and manifest realisations suffer. Indeed, it could be safely held thatpatterns of the total mode of existence in the $21^{\text {st }}$ century approximate to aggressive threats to human life and statehood.This paper decries this anomaly as a direct consequence of the rapid drift in morality from communally beneficial traditional values to unconscionable hybrid patterns inimical even to the individuals and groups involved.It thereforearticulates the annang fecund ideology 'imo ade awo' as the grand norm for reordering our scale of values as humans in order to guarantee human dignity, safety, development and by extension, foster community advancement in and beyond particular cultures.
\end{abstract}

Key words: 'Imo', 'Ade', 'Awo', 'Inyene'

\section{Conceptual Explications}

Concepts in want of explication hereare: 'imo', 'ade' and 'awo'. 'Imo', very simply put, implies wealth. Yet, the conceptualization and usage of 'imo' transcends wealth merely considered as material wherewithal. 'Imo' in annanglanguage, literature and philosophy entails the valuables in entirety the highest of which is the human person (akuk ade akuk, awo ade inyene= money is money, only the human person is wealth). However, without neglecting the material wherewithal, 'imo' places equitable value on things like concern for one another especially at the point of need,dexterity/skilfulness, proficiency in techniques, valour, virtues, wisdom, and even the rather metaphysical rapport between the spirit world and the physical cosmos.In fact, 'Imo' could arguably be termed both the discrete and network of complex but complementary variables in nature capable of advancing human life and worth. It is whatever possesses the quality of adding value to the human person, be it conceptual, physical or relational. As such, even the climatic and whether conditions, the soil texture/ topography, the human population as well as the morality/religious orientation of the people are indispensable variables in the definition of 'imo'.

The concept 'ade' is an annang rendition of the English verb 'to be' or 'is'. Thus, 'ade' serves to moderate the relation of 'imo' to its predicate 'Awo'. Hence, it predicates 'Awo' of 'Imo' in a symmetrical and equivalent context. In this context, both terms could be either used as subject or predicate without losing its meaning. "Imo ade awo" and "Awo ade imo" therefore mean one and the same thing.

Awo, in itself, is the annang term for the human person. Awo, in annang language, literature and philosophy is a generic term for the human person. Hence, it does not on its own differentiate between sexes or ages.

\section{Imo Ade Awo As An Ideology}

"Imo ade awo" could literally be rendered in English language as 'wealth is the human person'. Again, as noted above that both 'imo' and 'awo' could be used as subject and predicate of each other, another possible English translation could be rendered 'the human person is wealth'. In either case, the first logical upshot from this phraseology is that "Imo ade awo" is not a mere adage, aphorism nor a mere saying.It very quickly strikes the mind for what it is, an answer to unasked humanist questions, "what is "imo' in relations to 'awo'?" and "what is 'awo'?" As an answer, "Imo ade awo" encapsulates the basic understanding of the human person in annang people's epistemology and metaphysics. Hence, it is an ideology.

As an ideology, "Imo ade awo"entails that nothing, and absolutely nothing other than the human person is worth the concept 'wealth'. As such, it places the human person above every other thing ever to be appreciated and cared for. What this implies is that the principle "Imo ade awo" is central to the annang man's self-worth, community consciousness, socio-political development and dimensions of transcendental relationships (both horizontal and vertical) necessary for his meaningful existence. These could be highlighted thus: 


\section{Imo Ade Awoas 'Personhood-ennobling ideology'}

The principle "Imo ade awo" is central to the annang man's understanding of the self, his self-worth, his idea of what he stands for, as well as how he ought to relate with fellow humans and the world at large. This is so because the traditional annang understanding of the human person is that ofa self-conscious entity endowed with intelligence, will, passion and power capable of influencing other aspects of the material and spiritual nature.Man, in annang cosmogony, is an aspect of the eternal universe. And this comes close to the thrust of personalism - a philosophical view which holds that the ultimate reality in the world is understandable in terms of persons whether as spiritual selves or actual entities(Outline history of philosophy, 275). "Imo ade awo" as an ideology, considers the human person as the sole determinant of the meaning and value of both life and the lived world. Hence, intelligibility of the universe lies at the wits of man. Again, the derivation of valuables and the determination of that which is of value all depend on the will and passion of man. But these do not exhaust how "Imo ade awo" ennobles personhood.

By defining the human person as wealth and so placing him/her above every other thing ever to be appreciated and cared for, "Imo ade awo" endows the human person with inalienable dignity and rights. It places man as the master of both himself and his environment. It makes man a being whose life is sacrosanct. It further sees man as the determinant of values especially moral values '...understood to be those that make a person good purely and simply as a person' ( Right and Reason,2) Thus, whereas arguments abound in the western world on the question of where and when life becomes human, an annang man naturally understands that human life begins at conception. In this sense, "Imo ade awo" stands against all shades of anti-life and inhuman ideologies like that of the pro-abortion advocates. It rejects, for instance, L.Summer's view that human personhood arrives only when "the foetus is sentient, able to feel and sense as a conscious being" (Abortion and Moral Theory,42). On the contrary, "Imo ade awo" holds thatpersonhood is endowed as a natural inherent quality at conception. "...whereas what enters into that unique union at conception are both necessary complements of the two sufficiently necessary substrates for the generative life of humans, the products of that union becomes human by a causal series efficacythat follows from the being of the sources." (Personhood and Personal Identity: a philosophical study, 17-18).

The annang man, therefore values human life even from conception. Hence, abortion culture is alien to the annang culture. "Imo ade awo" as an ideology decries the avalanche of abortion cases among annang youths of our day as an aberration, a far cry from the traditional values for human life. "Imo ade awo" holds that adequate appreciation of the human person would naturally prevent such destruction of life in the womb and other forms of anti-life behavioural patterns like assassinations, homicides, genocides, armed robbery and kidnapping.

"Imo ade awo" further entails that the human person is neither an object for experimentation nor a subject for any form of abuse like economic exploitations. Hence, employment with no commensurate remuneration amounts to modern slavery within the context of "Imo ade awo". Man must therefore be adequately appreciated and cared for. This point agrees with deontological ethical position of Immanuel Kant that 'persons have intrinsic value as ends in themselves' (Outline history of philosophy,275). No man should therefore be used as an object for another goal. "Imo ade awo" decries the instances of slavery, employment with no commensurate remuneration and wilful use of poor, unsuspecting and vulnerable youth (in fact, any human person) for rituals and tasks that would cost their lives as dehumanization of the person. "Imo ade awo" therefore makes the point that such anti life trends put the entire human race at the risk of auto annihilation. Hence, there is need to overhaul the trends.

\section{Imo Ade Awoas 'A Transcultural Humanist Ideology'}

The observation that 'imo ade awo' is personhood ennobling does not imply an exultation of the individual in contra disposition to his / her fellows. Rather, the exultation of the human person in 'imo ade awo' is common to all humans. Because it is common, it places all humans on equal status. Thus, in advocating attitudinal changes in behaviour for the advancement of the human person, 'Imo ade awo' anticipates the overall good of human beings the world over. By this intent, it suffices as a humanist ideology.Humanism is an approach in study, philosophy, world view or practice that focuses on human values and concerns (From Wikipedia, the free Encyclopaedia)

'Imo ade awo' is one of such approaches as it calls for a revaluation of the modern cultures with a view to overhauling anti human behaviours in order to advance the welfare of both individual persons and generality of the human race.In this sense, the principle 'imo ade awo', considers not a particular person as the fount of wealth. It advocates the appreciation human beings irrespective of tongue and tribe, occupational or religious disposition and any form of perceptible difference in the mode of existence. What this amounts to is the point that 'Imo ade awo' is not a culture bound philosophy of persons and community development. Though it arose in the traditional annang philosophic culture, what it stands for goes beyond annang culture. Hence, 'Imo ade awo' is a transcultural humanist philosophy. This is so because, 'Imo ade awo' advocates adequate appreciation 
of the human person irrespective of cultural affinity and or any other accidental differentia. It is transcultural also because, 'Imo ade awo' would fail to achieve its ultimate objective if it is not imbibed and promoted across cultures. This is why the principle of 'Imo ade awo' is not to be promoted only by a particular class of humans like teachers but by all persons from all works of life to include pastors, politicians, business men,women in all fields, students and others. 'Imo ade awo' also needs to be corroborated and promoted in other cultures. These observations, however, has lots of implications.

\section{Implications Ofimo Ade Awoas 'A Transcultural Humanist Ideology'}

Though some implications of the principle of 'Imo ade awo' have been highlighted under our consideration of the principle as a personhood ennobling ideology, further implications still abound.

First of all, 'imo ade awo' as articulated, comes as a clarion call for the revaluation of modern behavioural patterns which hitherto, pose danger /threats to human progress the world over. Hence, it is primarily an ethical advocacy in the interest of man as man. Thisfollows from the fact that 'imo ade awo'queries the rising spate of man's inhumanity to man, interstate rift and even the root causes of cold/ actual war between nations. The principle therefore entails that adequate respect (the lack of which is the root of animosity/hatred) for persons and nationhood be made central in our consideration of fellow humans in order to ensure/sustain peace and harmony in the world. 'Imo ade awo' therefore begins naturally from an annang philosophical stand point advocating an ethical revaluation of values not solely in the interest of the annang man but the entire human race. This is so because what affect one member of a class, gradually extends to affect other members of the same class as 'imo ade awo' understands; 'inamaayeniyakadep'; 'se 'kinamannaakpanayaanamannaudo'. These and similar axioms in annang philosophy encapsulates the annang conception of the universe as one (monist ideology) as well as our metaphysical notion of interconnectivity; humans are so naturally interconnected that an effect on one man somewhere impacts on every other man anywhere in the world albeit,sooner or later. This further explains another axiom which holds that ' atoknkumidim, edemetteadinwongo, edemekaayaanwong'( whoever urinates into the stream would either have his/her paternal or maternal relations to drink unsafe water).The principle therefore implies that geographic and cultural differences do not suffice to make any class of people autonomous and independent of others.

This transcultural dimensionality of the principle portrays yet its other dimension of reaching beyond the ordinary/ physical. 'Imo ade awo' is also transcendental. In as much as 'imo' in annang also imply the rather metaphysical rapport between the spirit world and the physical cosmos, the principle underscores that human life goes beyond the mere physical plane. As such, value need be adequately attached to the transcendental aspects of being. It makes the point that human life need not be considered in isolation from facts, known and unknown in the history of humans, especially memories of the ancestors, human -spirit rapport and indeed the entire gamut of religious awareness.

The principle therefore, calls for a revaluation of our modern God consciousness. How, in our day, does a worshipper think of God, relate with his/her God as well as allow his/her God consciousness to influence his/her relationship with fellow human beings and the environment? Does the incursion and in some cases, outright overthrow of one religious systemby another alien to a people better the people's God consciousness or leave them in a religious vacuum? How about the attitude of a people who, in their judgement, have embraced a certain new religion even as leaders of the new religion yet their lifestyles fall short of the tenets of that new religion? Again, are others who neither understand nor belief what they have embraced. Should our generation be allowed to remain with confused religious currents tossed about by all waves of opinions? How best can our God consciousness be articulate into an effective guide in our interpersonal and international relationships? Does the doctrinal difference in the judeo-christian and arab-islam religions suffice for some ontological difference in the personhood of the worshippers and so justify wanton animosity, disregard and destruction of one by the other? Above all, does the significant difference injudeo-christian religion which has dislodged the traditional religions introduce some lacuna in the connatural man-God worship pattern thereby dislodging the worshipper from his/her natural God?'Imo ade awo' makes the point that adequate answers to questions of the type above can guarantee a balanced and humane basis for harmonious and progressive living. By this token, the principle 'imo ade awo'is not humanistic solely from a secular perspective. It certainly acknowledges the religious dimension of the human person but queries the hitherto religious outlooks with a view to revaluating same in the interest of the human persons.

Another implication of the principle 'Imo ade awo' is the rejection of all forms of discrimination especially against women. The principle 'Imo ade awo' sees the human person as one and the same irrespective of sex and colour. Hence, there is no discrimination on sex, creed, colour, height, material wherewithal and or socio religious status. 'Imo ade awo' understands such differences as accidental to the ontologically necessary quality of humanness, hence, inconsequential.It therefore decries the unfortunate premium on over celebrating male children at birth as if the female children were not worth same celebration. And this begs the question of the ontological difference between the male and female children. The principle 'Imo ade awo'entails that equal 
respects should be given to every human person and opportunities equitably distributed. The principle 'Imo ade awo' further entails an all cooperative and mutually complementary relationship among humans. And this leads to the implication of the principle on community consciousness.

Imo Ade Awoas a principle directly promotes community consciousness and development. Because it considers personhood as one and interconnected, it brings the mind to quickly appreciate the community as persons writ large. And so, it enables the persons involved to develop great sense of bonding and solidarity as members of a group or place. With the understanding that the welfare of one could impact positively on others (etoisidahaikpongiforoakai), the principle encourages mutual supports and collaborations even in the development of common facilities like roads, markets, assembly halls and the like. It makes life in the state/ community worth living.

In addition to community consciousness, 'Imo ade awo' envisages a truly democratic system of governance. This follows from the annang understanding that 'obongisi 'bongo ikpong' which implies that the leader needs to carry his/her subjects along the paths of governance. But it does not promote insubordinate/obstinate followership (akikoibaibongokeidakakomkiet). What the principle envisages is a mutually responsible rapport between the governor and the governed. And for this to work, adequate representation is conditio sine qua non. No leader is encouraged to adopt a king/subject dictatorship where in the subjects' opinions amount to nothing; no leader is encouraged to stay aloof from his/her followers. The principle encourages mutual dialectics between the leadership and followership adequately moderated to avoid high jacking by political jobbers and possible distortion of facts through misrepresentations(uruaafon aka idem).

Moreover, the principle 'Imo ade awo' assigns onerous responsibility to the enlightened and political class. Among such responsibilities is the task of enlightening the public on the tenets of 'Imo ade awo' through schools, churches, the media, the family and avenues available to man. Again, the principle expects much collaboration among this class of leaders in terms of using their good offices to facilitate infrastructural development in the communities; human capital development to include community/ state educational scholarships; micro credit facilities for small and medium scale entrepreneurs and the likes. Above all, such leaders need to assume the role of think tanks for the people and offer guide/plan for the communities' futuristic development. In other words, it is the role of such leaders of thought to guide its youths on choice of careers and similar life enhancing ventures. The principle 'Imo ade awo' further requires a well ordered educational curricula for the reorientation of the people especially the youth. This follows from the principle's stance that the youth is the future of the human race. Hence, youth development need to be placed central in the affairs of the elites and all if the future is to be secured.

\section{Conclusion}

This paper sought to articulate the annang fecund ideology 'imo ade awo' as the grand norm for reordering our scale of values as humans in order to guarantee human dignity, safety, development and by extension, foster community advancement in and beyond particular cultures. Efforts have been made to demonstrate the principle 'imo ade awo' as a philosophic principle with superlative concern for the pragmatic good, nay, welfare and advancement of the human person. In our considerations so far, 'imo ade awo' suffices as a principle of trans cultural humanism which acknowledges both the secular and religious dimensions of the human person. What need to be added is that the principle 'imo ade awo' is also welfarist in as much as human welfare is its overall concern. This philosophy, as seen, has far reaching implications for all members of the human race even beyond the identified few.

In conclusion therefore, it must be observed that articulators and proponents of the fecund ideology 'imo ade awo' need to put in much time and other resources in order to propagate tenets of the ideology first, among the annang people for strategic self management and relevance in both state and national affairs against the hitherto histrionic self presentation of unguided individuals in human endeavours where they turn out incompetent andmisfits. Again, proponents of the principle 'imo ade awo' need to spread this principle beyond annang culture at least as a marketable aspect of our cultural heritage and an index for global peace and enhancement of the human person. However, sincerity must be imbibed in acknowledging that what is here articulated might not be exhaustive of the plausible contents and significance of 'imo ade awo'. Further researches on the principle are therefore encouraged. 


\section{References}

[1] Fagothey, A.Right and Reason ( $8^{\text {th }}$ ed.) London: Charlie E. Merrill Pub. 1986.

[2] Okon, Joseph A. "Rethinking the Idea of Human Personhood" In

[3] Personhood and Personal Identity: A philosophical

[4] StudyEd. M.F. Asiegbu and J.C. Chukwuokolo. Enugu: SNAAP Press 2010.Pp 15-19.

[5] Sumner, L.W. Abortion and Moral Theory. New Jersey: Princeton University Press. 1981.

[6] Sahakian, W, S. Outline History of Philosophy. Boston. University Press. 1971

[7] Wikipedia: free internet encyclopeadia 